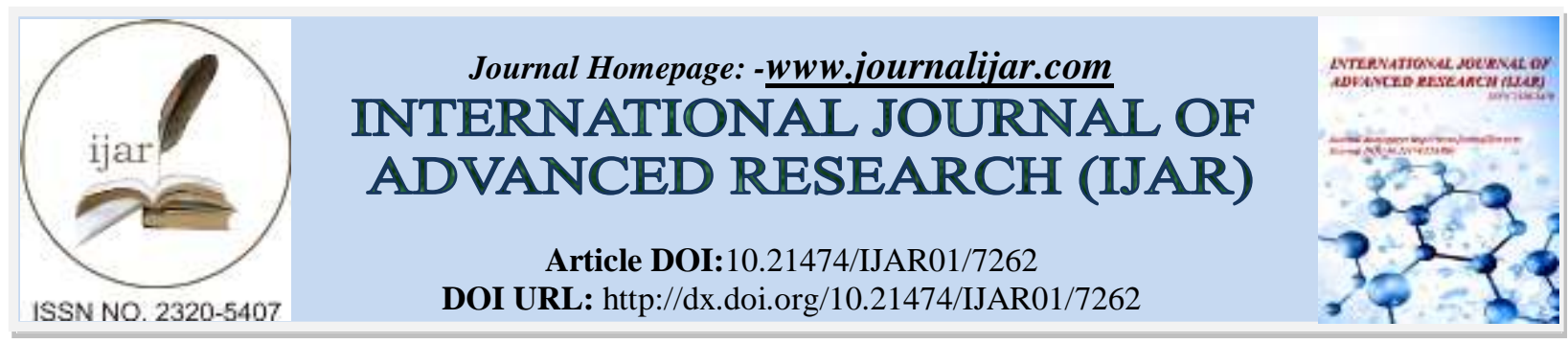

RESEARCH ARTICLE

\title{
AN INVENTORY MODEL FOR DETERMINING OPTIMAL TILES SIZE IN THE REPUBLIC OF YEMEN WITH WEIBULL DISTRIBUTION DEMAND.
}

\author{
Abdullah. M. A. Alshami and Najeeb. N. M. Maglas.
}

\section{Manuscript Info}

[..........................

Manuscript History

Received: 11 April 2018

Final Accepted: 13 May 2018

Published: June 2018

Keywords:-

Inventory-break-ability- A function of sell broken items -total cost function.

\begin{abstract}
This paper represented optimal ordering policy in an inventory control system for imported companies of tiles in Yemen. It is assumed that the demand data follows Weibull distribution; the break-ability rate of item and replenishment rate are constant. Also, an economic order quantity model is proposed to manage break-ability tiles. Initially, the present value of total cost during the planning horizon in this inventory system is modeled and further two phase's solution procedure is performed to derive the optimal order quantity. Finally, to obtain optimal quantity and optimal total cost for the collected data of tiles Company at Yemen the proposed model is implemented and better results were obtained and hence it represents the validity of the model.
\end{abstract}

Copy Right, IJAR, 2018,. All rights reserved.

\section{Introduction:-}

In real life literature review of inventory theory, it is assumed that the payment will be made to the vendor for the goods immediately after the receiving the consignment is relevant to economic policy for the companies of supplying. The several researchers have developed analytical inventory models with some considerations. Chang, et al (2010) presented the discount cash flows approach to the analysis of the optimal inventory policy in the presence of the trade credit Ghare, Schrader (1963), Goyal (1985). Since this literature reviews of study as Chung (1997), Goswami and Chaudhuri (1992), Covert, Philip (1973), Misra (1975), Elsayed and Teresi (1983), Donaldson (1977) used inventory replenishment policy for a linear trend in demand. Buzacott (1975) developed an economic order quantity model with the inflation rate. Pakkala, Achary (1992) developed deterministic -inventory model for deteriorating items with two warehouses and finite replenishment rate, Hwang, and Hahn (2000) proposed an optimal procurement policy for items with an inventory level-dependent demand rate and fixed lifetime. Teng and Chang (2005), Soni and Shah (2008), Stavrulaki (2011), Musa and Sani (2012), most of the researcher's Authors formulated model with infinite horizon demand of the items exist over infinite time. According to this assumption, keep product specification remains unchanged forever. Mishra (1973) formulated an inventory model with a variable rate of deterioration, a finite rate of production and no shortage. Goswami and Chaudhuri (1992) represented inventory model the deterioration rate is assumed to be proportional with time, the finite production rate to be proportional to the demand rate, the demand rate to be time-dependent with a linear positive trend. Silver and Meal (1973) developed an approximate solution procedure referred to as Silver, Meal Heuristic for the general case of deterministic time-varying demand pattern. Donaldson (1977) solve analytically the classical inventory policy for the case of the linear trend in demand. Cobbaert and Oudheusden (1996) developed Inventory models for fast moving spare parts subject to sudden death obsolescence. Breakability is defined as broken items cannot use it under any circumstances to sell it directly to the buyers. Enter in this model there is the case can add it as the items have breakability rate especially tiles with the ability to sell the breakable items as raw material for a local industry used 
them as small pieces, in the local tiles production to increase the quality as a strength that decreases the total cost for the items, because the cost of breakable items is not distributed to the cost of no breakable, Whatever if the break-ability rate occurs unintentionally or intentionally, so that is helpful to decrease the total cost. The management and holding inventories for breakable items become an important for inventory managers at the same time the minimization of total cost, there are many items having break-ability property as tiles with each types which are used for bathrooms, dining halls, kitchens, platforms of house and trains and many purposes, including Yemen as one world's countries as produced in Yemen or imported others companies at neighboring counties as Saudi companies of production tiles, Emirates, European, Egypt.

\section{Material and methods:-}

Collection of data:-

The sampling technique which is used in the collection of the data adopted the random sampling without replacement for the population where the population of the study is the export companies of tiles in SANAA capital of Yemen after that choosing the types of tiles randomly from a selected export company of tiles.

\section{Study of the area:-}

Yemen is the aimed area for inventory control system for perishable items as tiles whereas the export companies of tiles at Sanna are population, Saudi's tiles which are selected randomly from the export companies of tiles.

\section{Assumptions and notions:-}

Assumptions 2.3.1. Assumptions:-

The mathematical model in this paper is developed with the following assumptions

The planning horizon is finite.

1. Single item inventory control.

2. Breakability rate and function of sell broken items are constant.

3. Daily demand is uncertain is having Weibull distribution.

4. Breakability occurs as soon as the items are received into inventory.

5. The shortage is not allowed.

6. The inflation rate is constant and the time value of money.

7. The lead time is zero.

8. The inventory level at the end of the planning horizon will be nonzero.

9. The cost factors are deterministic.

10. The number of replenishments is restricted to one integer for satisfying the new order.

11. The total relevant cost consists of fixed ordering, purchasing, holding interest payable, Interest earned from sales revenue during the permissible period.

12. The last order is only being placed to satisfy the balance of the last period.

13. The goal of the model is to determine the fitted value for a breakable rate under which the net present value of total cost during the horizon planning is minimized.

Under the above assumptions following notations are used to develop the model

where.

\section{Notation:-}

$C_{p}=$ The present value of holding cost during the first replenishment cycle

$\mathrm{Q}=$ The order quantity in each replenishment.

$T C_{A}=$ The total fixed ordering cost $(0, \mathrm{~b})$.

$T C_{h}=$ The total holding cost $(0, \mathrm{~b})$.

$T C_{p}=$ The total purchasing cost $(0, \mathrm{~b})$.

$\varphi^{\prime}=$ Function sells of broken items during $(0, b)$

$\mathrm{TC}=$ the total relevant cost during $(0, \mathrm{~b})$.

\section{Parameters:-}

$\mathrm{A}=$ The fixed ordering cost per replenishment, \$lorder.

$\mathrm{C}=$ The unit purchasing price at time zero, $\$$ lorder.

$C(t)=$ The unit purchasing price at time t, $C(t)=C e^{-R T}$

$D(t)=$ The Weibull distribution demand per unit time. 
$\mathrm{b}=$ The length of the finite planning horizon.

$\mathrm{i}=$ the constant inflation rate.

$I(t)=$ The inventory level at time $t$.

$I_{c}=$ The interest charged per $\$$ per year by the supplier.

$I_{h}=$ The holding cost rate per unit time excluding interest charges.

$\mathrm{r}=$ The discount rate representing the time value of money.

$\mathrm{R}=\mathrm{r}-1$, representing the net constant discount rate of inflation.

$T=$ the length of each replenishment cycle.

$T_{j}=$ The total time that elapsed up to, including interest charges.

$t_{j}=$ The time at which the inventory level in the $j^{t h}$.

$\mathrm{V}=$ the unit selling price at time $\mathrm{t}$.

$\mathrm{V}(\mathrm{t})=$ the selling price per unit at time $\mathrm{t}, V(t)=V e^{-R T}$

$\theta=$ The constant break-ability rate, units/unit time.

$\varphi=$ The function of sell broken items.

\section{Mathematical model:-}

Let $I(t)$ is the inventory level at any time t, $0 \leq t \leq t_{1}$, Depletion due to demand and deterioration, breakability will occur simultaneously. The first order differential equation that describes the instantaneous state of $I(t)$ over the open interval $(0, b)$ is given by,

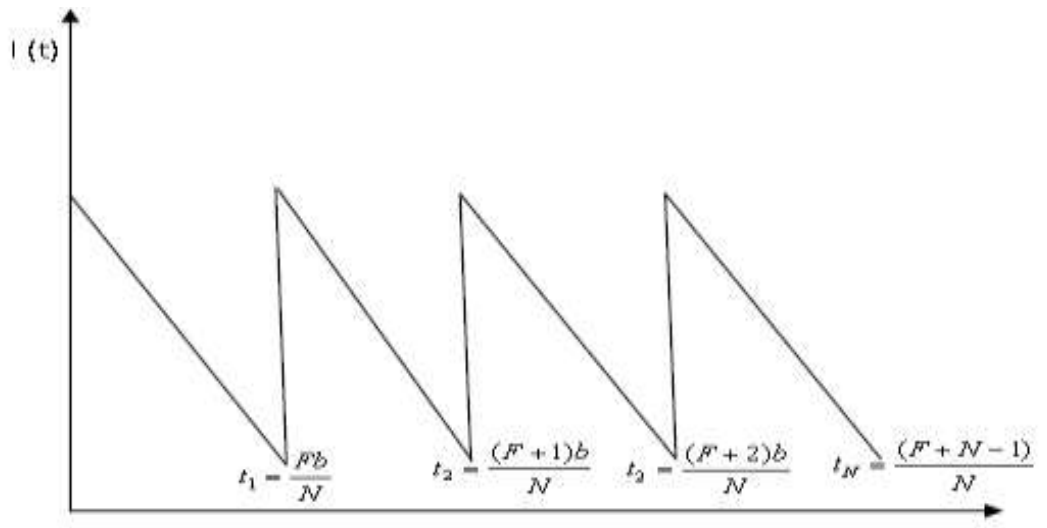

Tirne

Fig.1Graphical representation of the inventory control diagram

$\frac{d I(t)}{d t}+\theta I(t)-\alpha^{\prime} \varphi=-D(t), 0 \leq t \leq t_{1}, 0 \leq \varphi \leq \theta, 0 \leq \theta \leq 1$

$\frac{d I(t)}{d t}=-D(t), t_{1} \leq t \leq T$, Where $I\left(t_{1}\right)=0$ for the equation of number

$I(t)=I_{0}(t) \int_{t}^{t_{1}} D e^{\theta u} d u=\frac{\left(a-\alpha^{\prime} \varphi\right)}{\theta}\left(e^{\theta\left(t_{1}-t\right)}-1\right), I_{0}(t)=e^{-\theta t}$

$I(t)=\left(\frac{a-\alpha^{\prime} \varphi}{\theta}\right)\left(e^{\theta\left(t_{1}-t\right)}-1\right)$

The maximum inventory quantity at the begin each period is given as

$Q=\frac{\left(a-\alpha^{\prime} \varphi\right)}{\theta}\left(e^{\theta t_{1}}-1\right), t_{1}=\frac{F b}{N}$ 
Fixed ordering cost:-

We assumed the number of replenishment is $\mathrm{N}$ so that the fixed ordering cost over the planning horizon under the inflation consideration is:

$$
T C A=\sum_{j=0}^{N} A j T=\sum_{j=0}^{N} A e^{-j R T}=A\left[\frac{e^{-(N+1) R T}-1}{e^{-R T}-1}\right], \quad T=\frac{b}{N}
$$

Then

$$
T C A=\sum_{j=0}^{N} A j T=\sum_{j=0}^{N} A e^{-j R T}=A\left[\frac{e^{-(N+1) \frac{R b}{N}-1}}{e^{-\frac{R b}{N}-1}}\right]
$$

Holding cost excluding interest cost:-

We find the average inventory quantity to obtain holding cost

$$
\bar{I}=\int_{0}^{t_{1}} I(t) d t=\int_{0}^{t_{1}} \frac{a-\alpha^{\prime} \varphi}{\theta}\left[e^{\theta\left(t_{1}-t\right)}-1\right] d t=\frac{a-\alpha^{\prime} \varphi}{\theta^{2}}\left[e^{\theta t_{1}}-\theta t_{1}-1\right]
$$

By using Eq. (6) holding cost is obtained as follows

$$
T C h=\sum_{j=0}^{N-1} I h C{ }_{j} \bar{I}=\sum_{j=0}^{N-1} I h^{C} e^{-R j T}=\frac{\left(a-\alpha^{\prime} \varphi\right) C I}{\theta^{2}}\left[e^{\theta t_{1}}-\theta t_{1}-1\right]\left[\frac{e^{-N R T}-1}{e^{-R T}-1}\right]
$$

Since $T=\frac{b}{N}$ then Eq. (7) it will be as

$$
T C h=\frac{\left(a-\alpha^{\prime} \varphi\right) I h C}{\theta^{2}}\left[e^{\theta t_{1}}-\theta t_{1}-1\right]\left[\frac{e^{-R b}-1}{e^{\frac{-R b}{N}-1}}\right]
$$

\section{Purchasing cost:-}

The inventory level the purchasing cost of $j^{\text {th }}$ a cycle is calculated as (Fig. 1)

$$
C P(j)=C_{j I m}=C j\left[\frac{a-\alpha^{\prime} \varphi}{\theta}\left(e^{\theta t_{1}}-1\right)\right], j=1,2,3, \ldots . ., N
$$

The total purchasing cost over the planning horizon can be obtained as

Special case for total purchasing cost when

$$
T C p=\sum_{j=0}^{N-1} C P^{(j)}=\frac{C\left(a-\alpha^{\prime} \varphi\right)}{\theta}\left[e^{\theta t_{1}}-1\right]\left[\frac{e^{-R b}-1}{e^{\frac{-R b}{N}}-1}\right], T=\frac{b}{N}
$$

Total cost function:-

$$
T C=T C A+T C h+T C p
$$

Then,

$$
T C=A\left[\frac{e^{\frac{-(N+1) R b}{N}}-1}{e^{\frac{-R b}{N}}-1}\right]+\left[\begin{array}{l}
\frac{C I_{h} Q}{\theta}-C I_{h} \frac{\left(a-\alpha^{\prime} \varphi\right)}{\theta^{2}}\left(\left(\frac{2 \theta Q}{a-\alpha^{\prime} \varphi}+1\right)^{\frac{1}{2}}-1\right) \\
+C Q
\end{array}\right]\left[\begin{array}{l}
\frac{e^{-R b}-1}{e^{\frac{-R b}{N}}-1}
\end{array}\right]
$$




\section{Economic order quantity:-}

To find EOQ by minimizing the total cost function as

Since $t_{1}=\frac{F b}{N}$

$Q=\left(\frac{a-\alpha^{\prime} \varphi}{\theta}\right)\left(e^{\theta t_{1}}-1\right)$, By utilizing a truncated Taylor series for the

$e^{\theta t_{1}}$, about $t_{1}=0$, then

$e^{\theta t_{1}}=1+\theta t_{1}+\frac{\theta^{2} t_{1}^{2}}{2}$, after simplifying we can write $\mathrm{t}_{1}$ as a function in $\mathrm{Q}$ as the following equation

$t_{1}=\frac{1}{\theta}\left[\left(\frac{2 \theta Q}{a-\alpha^{\prime} \varphi}+1\right)^{\frac{1}{2}}-1\right]$

$T C=A\left[\frac{e^{\frac{-(N+1) R b}{N}}-1}{e^{\frac{-R b}{N}}-1}\right]+\left[\begin{array}{l}C I_{h} \frac{Q}{\theta}- \\ \left.C I_{h} \frac{1}{\theta^{2}}\left(a-\alpha^{\prime} \varphi\right)\left(\left(\frac{2 \theta Q}{a-\alpha^{\prime} \varphi}+1\right)^{\frac{1}{2}}-1\right)+\right] \\ C Q\end{array}\right]\left[\begin{array}{l}\left.\frac{e^{-R b}-1}{e^{\frac{-R b}{N}}-1}\right] \\ {\left[\begin{array}{l}\text { Substituting Eq. }(5,8,10) \text { in the Eq. (11) can be rewritten as } \\ \end{array}\right]}\end{array}\right.$

By taking derivate the Eq. 13 with respect to $Q$ to finding out the minimum value of total cost function then

$$
\frac{d T C}{d Q}=\frac{C I_{h}}{\theta}-\frac{C I_{h}}{\theta \sqrt{\frac{2 \theta Q}{a-\alpha^{\prime} \varphi}+1}}+C
$$

a) If $\left.Q \geq \frac{a-\alpha^{\prime} \varphi}{2 \theta}\right)\left(\left(\frac{C I_{h}}{C I_{h}+C \theta}\right)^{*}-1\right)\left(\frac{a-\alpha^{\prime} \varphi}{2 \theta}\right)$

This is an infeasible solution for the total cost function.

$$
\begin{gathered}
\text { b) if } Q<\frac{a-\alpha^{\prime} \varphi}{2 \theta} \\
Q^{*}=\left(1-\left(\frac{C I_{h}}{C I_{h}+C \theta}\right)^{2}\right)\left(\frac{a-\alpha^{\prime} \varphi}{2 \theta}\right)
\end{gathered}
$$


The obtained solution is a feasible solution for the total cost function.

$$
\frac{d^{2} T C}{d Q^{2}}=\frac{C I_{h}}{a-\alpha^{\prime} \varphi}\left(\frac{a-\alpha^{\prime} \varphi}{2 \theta Q}\right)^{\frac{3}{2}}\left[\frac{e^{-R b}-1}{\left.e^{\frac{-R b}{N}-1}\right]}\right]
$$

To test the value of $\mathrm{Q}^{*}$ in second order derivative if total

Since $\mathrm{Q}^{*}>0$

In the second case if

Then

$$
Q<\frac{a-\alpha^{\prime} \varphi}{2 \theta}
$$

$\frac{d^{2} T C}{d Q^{2}}>0$

The total cost function is having a minimum value at $\mathrm{Q}^{*}$ at second case 2

\section{Numerical examples:-}

Their table explains the sensitivity analysis represents the economic order quantity, optimal total cost as follows.

\section{Example:-}

Based on the data of the study area and estimate parameters of the daily demand distribution

Kolmogorov Smirnov. The goodness of fit for daily demand distribution as Weibull distribution is fitted at the level of significance at $10 \%, 5 \%$, and $1 \%$.

$$
t_{1}=\frac{F b}{N}, t_{1}=62 \text { days }
$$

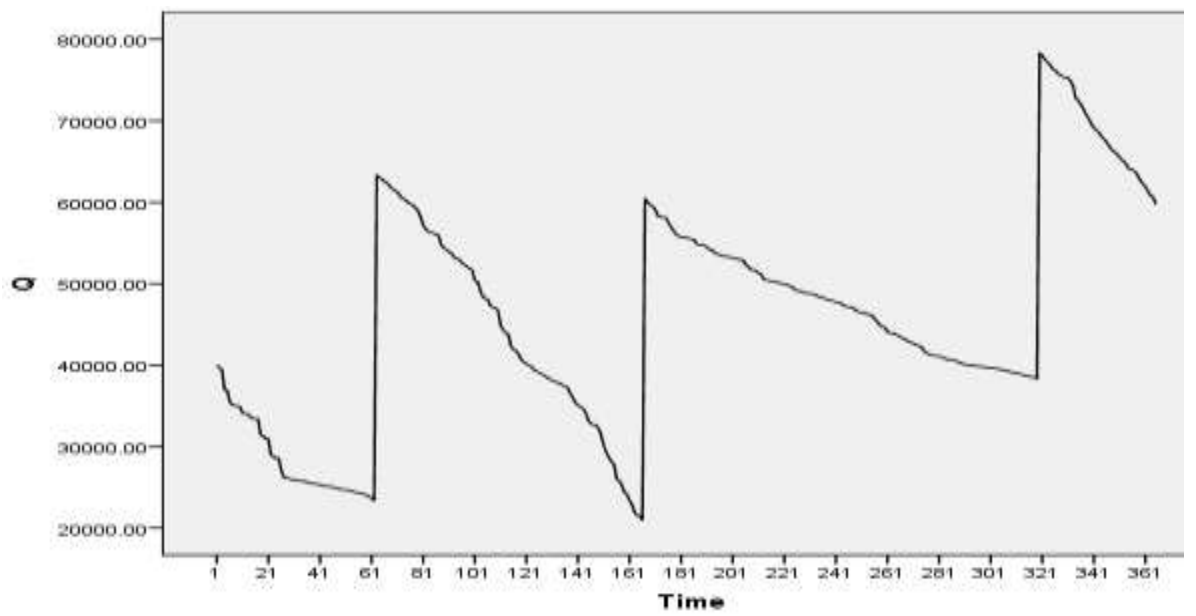

Fig2. Graphical representation of the inventory model of tiles

Then

$\mathrm{F}=0.533$, the first cycle of replenishment is equal to 62 days.

$$
\begin{aligned}
& I_{h}=0.005, R=0.05, b=365, A=1, C=7.5, N=3, \\
& \alpha=0.88577, \beta=249.67, \gamma=10, a=10.873, \varphi=\frac{\theta}{3}, \alpha^{\prime}=1
\end{aligned}
$$


Table1:-The sensitivity analysis

\begin{tabular}{|c|c|c|c|c|}
\hline$\Theta$ & $a-\alpha^{\prime} \phi$ & $\mathrm{D}$ & $\mathrm{Q}^{*}$ & $\mathrm{TC} *\left(\mathrm{Q}^{*}\right)$ \\
\hline 0.0000762 & 10.8837 & 350 & 2128.69 & 23366.30 \\
\hline 0.04 & 10.8704 & 200 & 49.40 & 380.94 \\
\hline 0.05 & 10.86706 & 2500 & 39.68 & 306.63 \\
\hline 0.1 & 10.8504 & 30 & 19.96 & 156.65 \\
\hline 0.2 & 10.81706 & 1400 & 10.00 & 81.31 \\
\hline 0.3 & 10.78373 & 430 & 6.67 & 56.20 \\
\hline 0.4 & 10.7504 & 48 & 5.00 & 43.64 \\
\hline 0.5 & 10.71706 & 55 & 4.00 & 36.11 \\
\hline 0.6 & 10.68373 & 102 & 3.33 & 31.09 \\
\hline 0.7 & 10.6504 & 800 & 2.86 & 27.51 \\
\hline 0.8 & 10.61706 & 22 & 2.50 & 24.82 \\
\hline 0.9 & 10.58373 & 39 & 2.22 & 22.73 \\
\hline 0.99 & 10.55373 & 400 & 2.02 & 21.21 \\
\hline 0.0000762 & 10.8837 & 200 & 782.34 & 6808.39 \\
\hline 0.04 & 10.8704 & 12 & 49.40 & 380.94 \\
\hline 0.05 & 10.86706 & 20 & 39.68 & 306.63 \\
\hline 0.1 & 10.8504 & 2000 & 19.96 & 156.65 \\
\hline 0.2 & 10.81706 & 108 & 10.00 & 81.31 \\
\hline 0.3 & 10.78373 & 356 & 6.67 & 56.20 \\
\hline 0.4 & 10.7504 & 12.5 & 5.00 & 43.64 \\
\hline 0.5 & 10.71706 & 2000 & 4.00 & 36.11 \\
\hline 0.6 & 10.68373 & 103 & 3.33 & 31.09 \\
\hline 0.7 & 10.6504 & 250 & 2.86 & 27.51 \\
\hline 0.8 & 10.61706 & 15 & 2.50 & 24.82 \\
\hline 0.9 & 10.58373 & 1500 & 2.22 & 22.73 \\
\hline 0.99 & 10.55373 & 850 & 2.02 & 21.21 \\
\hline 0.0000762 & 10.8837 & 65 & 782.34 & 6808.39 \\
\hline 0.04 & 10.8704 & 50 & 49.40 & 380.94 \\
\hline 0.05 & 10.86706 & 112 & 39.68 & 306.63 \\
\hline 0.1 & 10.8504 & 85 & 19.96 & 156.65 \\
\hline 0.2 & 10.81706 & 48 & 10.00 & 81.31 \\
\hline 0.3 & 10.78373 & 33 & 6.67 & 56.20 \\
\hline 0.4 & 10.7504 & 22 & 5.00 & 43.64 \\
\hline 0.5 & 10.71706 & 25 & 4.00 & 36.11 \\
\hline 0.6 & 10.68373 & 144 & 3.33 & 31.09 \\
\hline 0.7 & 10.6504 & 90 & 2.86 & 27.51 \\
\hline 0.8 & 10.61706 & 50 & 2.50 & 24.82 \\
\hline 0.9 & 10.58373 & 40 & 2.22 & 22.73 \\
\hline 0.99 & 10.55373 & 75 & 2.02 & 21.21 \\
\hline 0.0000762 & 10.8837 & 25 & 782.34 & 6808.39 \\
\hline 0.05 & 10.86706 & 140 & 39.68 & 306.63 \\
\hline 0.04 & 10.8704 & 70 & 49.40 & 380.94 \\
\hline 0.1 & 10.8504 & 10 & 19.96 & 156.65 \\
\hline 0.2 & 10.81706 & 20 & 10.00 & 81.31 \\
\hline 0.3 & 10.78373 & 89 & 6.67 & 56.20 \\
\hline 0.4 & 10.7504 & 60 & 5.00 & 43.64 \\
\hline 0.5 & 10.71706 & 80 & 4.00 & 36.11 \\
\hline 0.6 & 10.68373 & 125 & 3.33 & 31.09 \\
\hline 0.7 & 10.6504 & 32 & 2.86 & 27.51 \\
\hline 0.8 & 10.61706 & 17 & 2.50 & 24.82 \\
\hline 0.9 & 10.58373 & 35 & 2.22 & 22.73 \\
\hline 0.99 & 10.55373 & 130 & 2.02 & 21.21 \\
\hline
\end{tabular}




\begin{tabular}{|l|l|l|l|l|}
\hline 0.0000762 & 10.8837 & 64 & 782.34 & 6808.39 \\
\hline 0.05 & 10.86706 & 80 & 39.68 & 306.63 \\
\hline 0.04 & 10.8704 & 86 & 49.40 & 380.94 \\
\hline 0.1 & 10.8504 & 55 & 19.96 & 156.65 \\
\hline 0.2 & 10.81706 & 68 & 10.00 & 81.31 \\
\hline 0.3 & 10.78373 & 130 & 6.67 & 56.20 \\
\hline 0.4 & 10.7504 & 230 & 5.00 & 43.64 \\
\hline 0.5 & 10.71706 & 98 & 4.00 & 36.11 \\
\hline .6 & 10.68373 & $\mathbf{3 5 0}$ & 3.33 & 31.09 \\
\hline
\end{tabular}

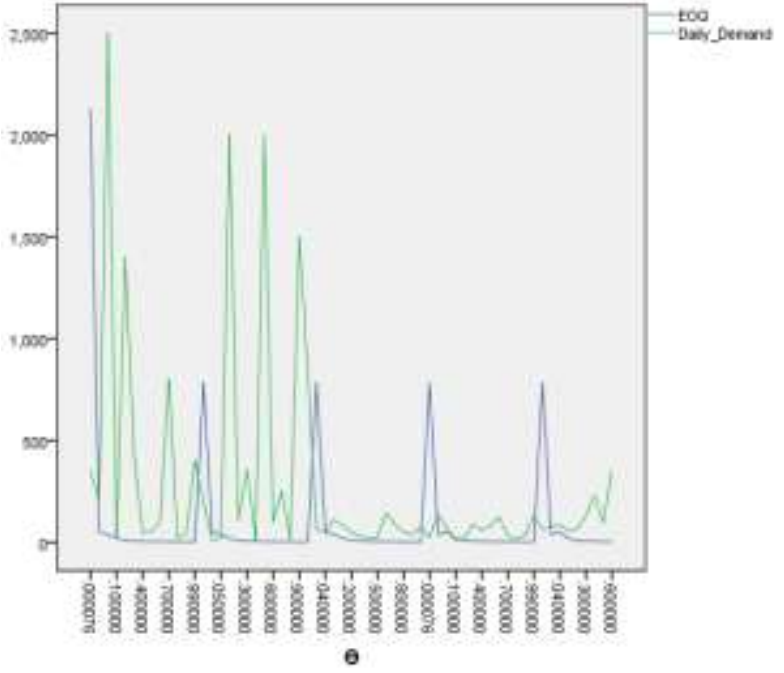

Fig 3:-Graphical representation EOQ, daily demand VS break-ability rate

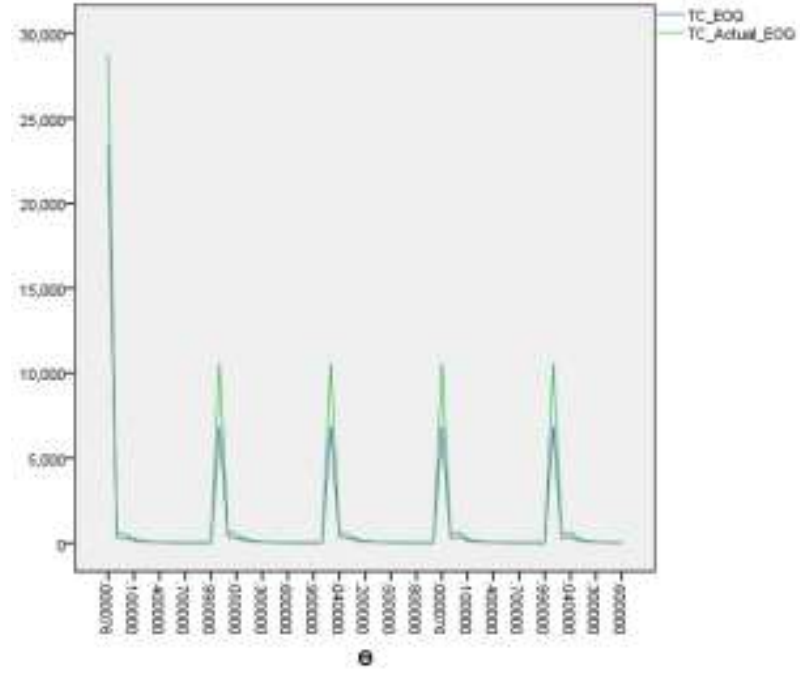

Fig 4:-Graphical representation actual total cost, optimal total cost VS break-ability rate

\section{Conclusion:-}

In this paper, a new parameter i.e. sell function is represented as of broken tiles to reduce the total cost it. The output of the proposed mathematical model for obtaining the optimal total cost of tiles and obtaining the economic order quantity for several breakable rates are calculated and compared with the standard breakable rate of tiles. The economic order quantity was decreased as the breakable rate increases so that the total cost of tiles is decreased as the order economic quantity decreased. The output of the inventory model showed the optimal total cost, an economic order quantity for the collected data, first time cycle with 0.0000762 as breakable rate obtained in maximum value with low-risk level as breakability rate whereas, it would be at a minimum value when risk was increasing. The impression about the output of the proposed model for the tiles items is the committed policy of imported industry of tiles at Yemen is useful with low-risk level as breakability rates of tiles with the procedure of selling broken items for a local industry tile to minimize the total cost. The economic order quantity is feasible whatever the values of the breakability rate and optimal total cost also. This makes the proposed model is applicable under any risk level. The suggestion for the imported industry of tiles at Yemen to maintain the risk level as the safely level $0.0762 \%$ and adopted the proposed model to take the decision for the economic order quantity. 


\section{References:-}

1. Buzacott.J.A. (1975). Economic order quantities with inflation. Operational Research Quarterly, 26 553-558.

2. Chang. C.T, Ouyang. L.Y, Teng .J.T, Cheng .M.C. (2010). Optimal ordering policies for deteriorating items using discounted cash-flow analysis when a trade credit is linked to order quantity. Comput.Ind.Eng, 59, 770777.

3. Chung .K.J. (1997). A theorem on the deterioration of economic order quantity under conditions of permissible delay in payments. Comput.Oper.Res , $25,49-52$.

4. Cobbaert. K, Oudheusden . D. V. (1996). Inventory models for fast moving spare parts subject to sudden death obsolescence. Int.J.Prod.Econ, 44,239-248.

5. Covert .R.P, G.C.Philip. (1973). An EOQ model for items with Weibull distribution. AIIE Transactions, 5,323326.

6. Donaldson.W.A. (1977). Inventory replenishment policy for a linear trend in demand. An analytic solution. Operational Research Quarterly, 28,663-67).

7. Elsayed.E.A, C.Teresi. (1983). Analysis of inventory system with deteriorating items. International Journal of Production Research, 21, 449-460.

8. Ghare .P.M, Schrader.G.P. (1963). model for an exponentially decaying inventory. J.Ind.Eng, 14, 238-243.

9. Goswami, Chaudhuri.K.S. (1992). Variations of order level inventory models for deteriorating items. International .J.Production.Econ, 27, 111-117.

10. Goyal.S.K. (1985). Economic order quantity under conditions of permissible delay in payments. J.Oper.Res.Soc , 36,335-338.

11. Hwang, H, Hahn, K.H. (2000). An optimal procurement policy for items with an inventory level-dependent demand rate and fixed lifetime. European Journal of Operational Research, 127, 537-545.

12. Mishra.R.B. (1973). Optimum production lot size model for a system with deteriorating inventory. International .J.production research , $13,495-505$.

13. Misra.R.P. (1975). Optimum production lot size model for a system with deteriorating inventory. International Journal of Production Research, 13, 495-505.

14. Musa.A, Sani. B. (2012). Inventory ordering policies of delayed deteriorating items under permissible delay in payments. International Journal of Production Economics, $136,75-83$.

15. Pakkala.T.P.M, Achary.A, Manoranjan. (1992). Adeterministic inventory model for deteriorating items with two warehouses and finite replenishment rate. European Journal of Operation Research, 57,71-76.

16. Ray .J, Chaudhuri. K.S. (1997). An EOQ model with stock dependent demand, shortage, inflation and time discounting. Int.J.Prod.Econ, 53, 171-180.

17. Silver.E.A, Meal.H.C. (1973). A Heuristic for selecting of lot size quantities for the case of deterministic timevarying demand rate and discrete opportunities for replenishment. Prod.Invent.Mgmt, 14, 64-74.

18. Soni. H, Shah. N.H. (2008). Optimal ordering policy for stock-dependent demand under a progressive payment scheme. European Journal of Operational Research, 184, 91-100.

19. Stavrulaki.E. (2011). Inventory decisions for substitutable products with stock- dependent demand. International Journal of Production Economics, $129,65-78$.

20. Teng, J.T., Chang, C.T. (2005). Economic production quantity models for deteriorating items with a price- and stock-dependent demand. Computers and Operations Research, 32,297-308. 